Pacific Journal of Mathematics

INTERSECTIONS OF $M$-IDEALS AND $G$-SPACES

G. H. OLSEN AND U. UTTERSRUD 


\title{
INTERSECTIONS OF $M$-IDEALS AND $G$-SPACES
}

\author{
Å. Lima, G. H. OlsEN AND U. UTtersRud
}

A closed subspace $N$ of a Banach space $V$ is called an $L$-summand if there is a closed subspace $N^{\prime}$ of $V$ such that $V$ is the $1_{1}$-direct sum of $N$ and $N^{\prime}$. A closed subspace $N$ of $V$ is called an $M$-ideal if its annihilator $N^{\perp}$ in $V^{*}$ is an $L$-summand. Among the predual $L_{1}$-spaces the $G$-spaces are characterized by the property that every point in the $w^{*}$-closure of the extreme points of the dual unit ball is a multiple of an extreme point. In this note we prove that if $V$ is a separable predual $L_{1}$-space such that the intersection of any family of $M$-ideals is an $M$-ideal, then $V$ is a $G$-space.

The notions of $L$-summands and $M$-ideals were introduced by Alfsen and Effros [1] who showed that they play a similar role for Banach spaces as ideals do for rings. The intersection of a finite family of $M$-ideals in a Banach space is an $M$-ideal, but as shown by Bunce [2] and Perdrizet [5] the intersection of an arbitrary family of $M$-ideals in a Banach space need not be an $M$-ideal. However, Gleit [3] has shown that if $V$ is a separable simplex space, then $V$ is a $G$-space if and only if the intersection of an arbitrary family of $M$-ideals is an $M$-ideal. Later on, Uttersrud [7] proved that in $G$-spaces intersections of arbitrary families of $M$-ideals are $M$-ideals. Then N. Roy [6] gave a partial converse when she proved that if in a separable predual $V$ of $L_{1}$ the intersection of an arbitrary family of $M$-ideals is an $M$-ideal then $V$ is a $G$-space. Here we present a short proof of this result.

THEOREM. Let $V$ be a separable predual $L_{1}$-space. Then $V$ is a $G$-space if and only if the intersection of any family of $M$-ideals in $V$ is an $M$-ideal.

Proof. As already mentioned the only if part is proved in [7]. For the if part we will show that

$$
\overline{\partial_{e} V_{1}^{*}} \subseteq[0,1] \partial_{e} V_{1}^{*}
$$

where $\partial_{e} V_{1}^{*}$ denotes the set of extreme points in the unit ball $V_{1}^{*}$ of $V^{*}$. It then follows from [4] that $V$ is a $G$-space. To this end let $\left\{x_{n}^{*}\right\}_{n=1}^{\infty}$ be a convergent sequence of mutually disjoint extreme points in $V_{1}^{*}$, say $x_{0}^{*}=w^{*}-\lim x_{n}^{*}$. For each $n$, let

$$
N_{n}=\text { norm-closure } \operatorname{lin}\left\{x_{0}^{*}, x_{n}^{*}, x_{n+1}^{*}, \ldots\right\} .
$$


Let $c$ denote the space of convergent sequences and define a linear operator $T: V \rightarrow c$ by

$$
T x=\left(x_{n}^{*}(x)\right)_{n=1}^{\infty} .
$$

We identify $c$ with the space of continuous functions on the one point compactification $\mathbf{N} \cup\{\infty\}$ of the natural numbers $\mathbf{N}$ and we let $e_{n}^{*}$ be the point mass in $n, e_{0}^{*}$ the point mass in $\infty$. Then

$$
T^{*} e_{n}^{*}=x_{n}^{*}, \quad n=1,2, \ldots
$$

And consequently

$$
T^{*} e_{0}^{*}=x_{0}^{*} .
$$

Since $\left(x_{n}^{*}\right)_{n=1}^{\infty}$ is equivalent with the usual basis of $1_{1}$ we observe that for each $n$

$$
T^{*}\left(\text { norm-closure } \operatorname{lin}\left\{e_{0}^{*}, e_{n}^{*}, e_{n+1}^{*}, \cdots\right\}\right)=N_{n} .
$$

Since, by a well-known category argument, the range of a dual map is norm closed if and only if it is $w^{*}$-closed, it follows that $N_{n}$ is $w^{*}$-closed for each $n$. Now the dual statement of our assumption gives that the $w^{*}$-closure of arbitrary sums of $w^{*}$-closed $L$-sumands is an $L$-summand, so since an extreme point in the unit ball of an $L_{1}$-space spans an $L$-summand we get that $N_{n}$ is a $w^{*}$-closed $L$-summand. Therefore

$$
\bigcap_{n=1}^{\infty} N_{n}=\operatorname{lin}\left\{x_{0}^{*}\right\}
$$

is an $L$-summand. Hence $x_{0}^{*}=0$ or $x_{0}^{*} /\left\|x_{0}^{*}\right\|$ is an extreme point, and the proof is complete.

\section{REFERENCES}

1. E. M. Alfsen and E. G. Effros, Structure in Banach spaces I \& II, Ann. of Math., 96 (1972), 98-173.

2. J. Bunce, The intersections of closed ideals in a simplex space need not to be an ideal, J. London Math. Soc., 2 (1969), 67-68.

3. A. Gleit, $A$ characterization of $M$-spaces in the class of separable simplex spaces, Trans. Amer. Math. Soc., 169 (1972), 25-33.

4. H. E. Lacey, The isometric theory of classical Banach spaces, Springer Verlag 1974.

5. F. Perdrizet, Espaces de Banach ordonnés et ideaux, J. Math. Pures et Appl., 49 (1970), 61-98.

6. N. M. Roy, An M-ideal characterization of G-spaces, Pacific J. Math., 92 (1981), $151-160$.

7. U. Uttersrud, On M-ideals and the Alfsen-Effros structure topology, Math. Scand., 43 (1978), 369-381. 
Received February 10, 1981.

AgRicultural UNIVERSITY OF NORWAY

1432 AAS-NLH, NORWAY

AND

TELEMARK DH-SKole

3800 BØ I TelEMarK, NoRWAY 



\section{PACIFIC JOURNAL OF MATHEMATICS \\ EDITORS}

DONALD BABBITT (Managing Editor)

University of California

Los Angeles, CA 90024

\section{Hugo Rossi}

University of Utah

Salt Lake City, UT 84112

C. C. Moore and Arthur Ogus

University of California

Berkeley, CA 94720
J. DugundiI

Department of Mathematics

University of Southern California

Los Angeles, CA 90089-1113

R. FINN and H. SAMELSON

Stanford University

Stanford, CA 94305

ASSOCIATE EDITORS
R. ARens
E. F. BECKENBACH
B. H. NeumanN
F. WOLF
K. YoshidA (1906-1982)

\section{SUPPORTING INSTITUTIONS}

UNIVERSITY OF ARIZONA

UNIVERSITY OF BRITISH COLUMBIA

CALIFORNIA INSTITUTE OF TECHNOLOGY

UNIVERSITY OF CALIFORNIA

MONTANA STATE UNIVERSITY

UNIVERSITY OF NEVADA, RENO

NEW MEXICO STATE UNIVERSITY

OREGON STATE UNIVERSITY
UNIVERSITY OF OREGON

UNIVERSITY OF SOUTHERN CALIFORNIA

STANFORD UNIVERSITY

UNIVERSITY OF HAWAII

UNIVERSITY OF TOKYO

UNIVERSITY OF UTAH

WASHINGTON STATE UNIVERSITY

UNIVERSITY OF WASHINGTON 


\section{Pacific Journal of Mathematics}

Vol. 104, No. 1

May, 1983

Nestor Edgardo Aguilera and Eleonor Ofelia Harboure de Aguilera, On

the search for weighted norm inequalities for the Fourier transform $\ldots \ldots .1$

Jin Akiyama, Frank Harary and Phillip Arthur Ostrand, A graph and its complement with specified properties. VI. Chromatic and achromatic numbers ......................................... 15

Bing Ren Li, The perturbation theory for linear operators of discrete type . . . 29

Peter Botta, Stephen J. Pierce and William E. Watkins, Linear

transformations that preserve the nilpotent matrices .............. 39

Frederick Ronald Cohen, Ralph Cohen, Nicholas J. Kuhn and Joseph

Alvin Neisendorfer, Bundles over configuration spaces .......... 47

Luther Bush Fuller, Trees and proto-metrizable spaces . . . . . . . . . . 55

Giovanni P. Galdi and Salvatore Rionero, On the best conditions on the

gradient of pressure for uniqueness of viscous flows in the whole space . . 77

John R. Graef, Limit circle type results for sublinear equations $\ldots \ldots \ldots \ldots 85$

Andrzej Granas, Ronald Bernard Guenther and John Walter Lee,

Topological transversality. II. Applications to the Neumann problem for

$y^{\prime \prime}=f\left(t, y, y^{\prime}\right) \ldots \ldots \ldots \ldots \ldots \ldots \ldots \ldots \ldots \ldots \ldots \ldots \ldots \ldots \ldots . \ldots 5$

Richard Howard Hudson and Kenneth S. Williams, Extensions of

theorems of Cunningham-Aigner and Hasse-Evans . . . . . . . . . . . 111

John Francis Kurtzke, Jr., Centralizers of irregular elements in reductive algebraic groups

James F. Lawrence, Lopsided sets and orthant-intersection by convex

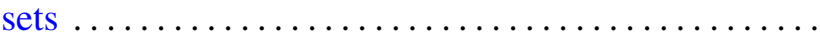

Åsvald Lima, G. H. Olsen and U. Uttersrud, Intersections of $M$-ideals and

$G$-spaces

Wallace Smith Martindale, III and C. Robert Miers, On the iterates of derivations of prime rings

Thomas H. Pate, Jr, A characterization of a Neuberger type iteration procedure that leads to solutions of classical boundary value problems

Carl L. Prather and Ken Shaw, Zeros of successive iterates of multiplier-sequence operators

Billy E. Rhoades, The fine spectra for weighted mean operators

Rudolf J. Taschner, A general version of van der Corput's difference theorem

Johannes A. Van Casteren, Operators similar to unitary or selfadjoint ones 